\title{
CONVERGÊNCIAS E DIVERGÊNCIAS DA RELAÇÃO ESCOLA E FAMÍLIA PARA UM IDEAL DEMOCRÁTICO
}

\section{ARTIGO DE REVISÃO}

BEZERRA, Maria Janaina Oliveira 1, PINHEIRO, Gisêlda Maria da Silva 2, NASCIMENTO, Maria Lidiana do ${ }^{3}$, NASCIMENTO, Maria Luciene do ${ }^{4}$, GOMES, Maria Tereza de Souza ${ }^{5}$, SIQUEIRA, Wdemira Silva de Aguiar ${ }^{6}$, NASCIMENTO, Maria do Livramento de Freitas ${ }^{7}$, SILVA, Robson José de Moura ${ }^{8}$

BEZERRA, Maria Janaina Oliveira. Et al. Convergências e divergências da relação escola e família para um ideal democrático. Revista Científica Multidisciplinar Núcleo do Conhecimento. Ano 06, Ed. 05, Vol. 02, pp. 145-162. Maio de 2021. ISSN: 2448-0959, Link de acesso: https://www.nucleodoconhecimento.com.br/educacao/relacao-escola

\section{RESUMO}

O presente estudo discute as relações convergentes e divergentes da relação escola e família para um ideal democrático, sob os vieses pedagógicos, sociais e políticos.

\footnotetext{
${ }^{1}$ Mestranda em Ciências da Educação.

2 Mestranda em Ciências da Educação.

${ }^{3}$ Mestranda em Ciências da Educação.

${ }^{4}$ Mestranda em Ciências da Educação.

${ }^{5}$ Mestranda em Ciências da Educação.

${ }^{6}$ Mestranda em Ciências da Educação.

${ }^{7}$ Mestranda em Ciências da Educação.

${ }^{8}$ Orientador.
}

RC: 84460

Disponível em: https://www.nucleodoconhecimento.com.br/educacao/relacao-escola 
Trata-se, portanto, de um estudo direcionado ao contraste entre as múltiplas relações familiares, educacionais e sociais. $O$ objetivo central deste estudo ancora-se no intuito de se apresentar uma visão panorâmica e abrangente quanto à influência das relações familiares, sociais e ambientais sobre os processos de ensino-aprendizagem. Nossa fundamentação teórica conta com as contribuições de autores, como Kreppner (2000), Polônia e Dessen (2007), Paro (2002), Silva (2019), Almeida (2018), Almeida (2018), Pimenta (1991), Pimenta (2014), Silva (2014) e outros. A metodologia adotada pauta-se na abordagem qualitativa e na pesquisa bibliográfica. Os resultados do estudo apontam para abordagens preparatórias de natureza escolar quanto sua influência sobre as ações familiares e, consecutivamente, ao processo de aprendizagem.

Palavras-Chave: Escola e Família, Processos de Ensino-Aprendizagem, Abordagens Preparatórias.

\section{INTRODUÇÃO}

A família e a escola são duas instituições cujas funções integram-se e deslocam-se em um fluxo contínuo, mantenedor e renovador. família e escola naturalmente detêm, na sociedade, a abrangência educacional, responsável pelo processo evolutivo dos sujeitos, da cultural, das expressões afetivas e emotivas, dos conceitos étnicos em comunidade, isto é, tanto uma quanto a outra podem impulsionar ou inibir o crescimento expressivo dos indivíduos em uma mesma sociedade. Todavia, se de um lado a família e a escola são codependentes no processo de formação dos indivíduos, são igualmente autônomas no sentido de que suas funções são diferentes e têm características próprias.

Não raramente ocorrem disparidades de direções e sentidos, bem como quando a precariedade da estrutura familiar ou escolar que dificultam e atravancam o processo de formação de crianças e jovens. Diante desta conjectura, são fartos os estudos que apontam como fatores de insucesso escolar a situação social de crianças vítimas de

RC: 84460

Disponível em: https://www.nucleodoconhecimento.com.br/educacao/relacao-escola 
uma desestrutura familiar de risco, da violência e do abuso domésticos, da desigualdade social e, consequente, da precariedade socioeconômica.

Da mesma forma, escolas desestruturadas materialmente, despreparadas para o exercício de sua função social, sem uma política pedagógica consistente, viva e coerente são causadoras de danos cognitivos capazes de retardar o desenvolvimento social das crianças e jovens. Em função disto, é imprescindível que haja maior integração e coparticipação entre estas instituições para que ambos sejam espaços efetivos de formação e transformação da sociedade.

Com base nestas considerações, discutiremos neste artigo duas linhas de pensamento: primeiramente as formas de influência da família no desempenho escolar, considerando tanto a influência da família de forma involuntária, em função de sua estrutura (pelas mais diversas formas de constituição de seu núcleo), seus valores éticos e vínculos culturais, como a voluntariamente no sentido do grau de compreensão e interação que a própria família estabeleça com a instituição escolar.

A seguir, conduziremos a argumentação ao reafirmar a importância da relação família/escola, apontando de que forma a escola pode encontrar meios de consolidar esta interação tão significativa para a formação dos indivíduos.

\section{REFERENCIAL TEÓRICO}

\subsection{FAMÍLIA, DESEMPENHO ESCOLAR E CONFLITOS DE RELAÇÃO}

A função da família e sua importância no desenvolvimento da personalidade de um indivíduo são indiscutíveis, pois se trata da célula inicial de formação da criança, onde se firmam os valores morais e culturais. A primeira função da família é propiciar proteção, condições de bem-estar físico e emocional à criança. Aliados a isto, somamse a transmissão e continuidade dos valores e crenças que sustentam determinado grupo social e asseguram o enlace e a interação da criança com o meio cultural em que vive (KREPPNER, 2000).

RC: 84460

Disponível em: https://www.nucleodoconhecimento.com.br/educacao/relacao-escola 
No seio familiar, a criança elabora seu repertório cultural, se firma gradativamente como sujeito social, apreendendo os significados que lhe permitirão interagir e/ou, até mesmo, transformar a sociedade, influenciando-a, inclusive, através de novas formas de concepções familiares.

Cabe, portanto, à família, tanto a formação cognitiva e emocional do sujeito quanto propiciar a interseção deste com outros ambientes sociais, entre os quais se inclui a escola, numa cadeia dinâmica de relações que constitui a espiral do desenvolvimento integral da pessoa.

Diante disso, Polônia e Dessen (2007) concluem que:

Como primeira mediadora entre o homem e a cultura, a família constitui a unidade dinâmica das relações de cunho afetivo, social e cognitivo que estão imersas nas condições materiais, históricas e culturais de um dado grupo social. Ela é a matriz da aprendizagem humana, com significados e práticas culturais próprias que geram modelos de relação interpessoal e de construção individual e coletiva (POLÔNIA; DESSEN, 2007, p.22).

A escola, por sua vez, como instituição de ensino, tem como função primeira naturalmente a transmissão do conhecimento acumulado pela humanidade. Seu papel é preponderante no processo civilizacional, de modo que, diferentemente da família, precisa sistematizar o processo educacional, uma vez que tem objetivos e metas a cumprir. Todavia, não lhe cabe apenas a veiculação insensível do saber escolarizado, mas inseri-lo crítica e criativamente na dinâmica social, fazendo com que o estudante transforme também seu conhecimento construído pela família para se posicionar com sujeito ativo na sociedade. Em função disso, é que família e escola se tocam e se fundem, tornando fundamental que se aproximem e dialoguem, buscando objetivos comuns para efetivamente favorecer o crescimento cognitivo de crianças e jovens (POLÔNIA; DESSEN, 2007).

Além disso, a escola consiste num ambiente de relações interpessoais extremamente complexas, uma vez que congrega uma diversidade de pessoas com valores culturais muito particulares. No ambiente escolar, faz-se imprescindível construir laços de RC: 84460

Disponível em: https://www.nucleodoconhecimento.com.br/educacao/relacao-escola 
afetividade entre alunos oriundos de famílias com perspectivas e visões de mundo diversas. Emerge deste fato a necessidade de que, não apenas o aluno, mas, também, suas famílias interajam e participem do contexto escolar para compreendêlo e assimilá-lo aos seus próprios valores e favorecerem e fortalecerem os vínculos de afetos dos seus filhos no ambiente escolar (POLÔNIA; DESSEN, 2007).

Cabe a escola, nesse contexto de pluralidade, preparar os alunos e respectivamente suas famílias para conviverem com as diferenças e superarem possíveis conflitos, oriundos e emergentes de tais relações. Se a instituição de ensino não tem em sua proposta político-pedagógica a construção de vínculos num ambiente de diversidade, também não conseguirá atingir com eficiência os objetivos da escolarização.

Nesse sentido, Paro (2002) explana que:

O desafio das escolas hoje é sair dos extremos, buscando valorizar tanto a informação, como a formação, tanto o educador como o educando, tanto o método como os conhecimentos acumulados historicamente, resgatando ainda, a importância do grupo na construção de conceitos e valores (PARO, 2002, p.57).

Atualmente, é preciso que a escola se aproprie das diversas formas de composição familiar, compreendendo que este não necessariamente se apresenta como um grupo social composto por pai, mãe e filhos que compartilham um mesmo ambiente. Como todas as esferas da sociedade, a instituição familiar é mutável e segue as transformações históricas. Essas mudanças são igualmente geradoras de tensões e conflitos que ultrapassam os muros da escola. Diante desta nova realidade, é imprescindível que a escola acompanhe política e, pedagogicamente, as metamorfoses da sociedade, revendo constantemente suas metodologias, inclusive no contexto da escola pública em que muitas vezes a comunidade não conta com uma rede pública de apoio, para o caso de crianças cujas famílias desenvolvam padrões de relacionamento disfuncionais, em que subjazem situações de violência, abusos e maus tratos (PARO, 2002).

RC: 84460

Disponível em: https://www.nucleodoconhecimento.com.br/educacao/relacao-escola 
Entretanto, as características dos novos tempos no seio familiar e suas transformações no processo de modernização da sociedade não devem justificar o fracasso escolar, nem tão pouco, o educador encontrar nestas transformações elementos que desculpem o resultado negativo de um trabalho. Estudos mostram que a presença da família, independente da sua composição, no ambiente escolar pode desenvolver atitudes e comportamentos positivos. A maneira de educar, de auxiliar nas situações-problemas e a relação de afetividade refletem, diretamente, na maneira do agir sobre a vida (PARO, 2002).

Para Souza (2017):

\begin{abstract}
A família, primeiro núcleo social de convivência, e a escola são os dois contextos que mais exercem influência na aprendizagem e no desenvolvimento da criança, pois são os primeiros contextos a fazer a mediação dela com o meio cultural. Família e escola, portanto, respondem conjuntamente pela bagagem de formação que essa criança levará para a vida adulta (SOUZA, 2017, p.24).
\end{abstract}

Destarte, é preciso que nos conscientizemos que a influência da família sempre será um fato substancial no processo de ensino-aprendizagem, seja pela presença, seja pela ausência, seja por estabelecer vínculos sólidos e confluentes com os objetivos da instituição escolar, seja em função das disfunções e desestruturas, em qualquer das situações, pois meio a essas relações estará a família provocando efeitos positivos ou negativos, promovendo o sucesso ou o fracasso dos alunos. Esta onipresença da família se reflete nas mais diversas formas entre crianças e jovens: bom desempenho ou dificuldades de aprendizagem, proatividade ou atitudes de indisciplina, capacidade de socialização ou comportamentos antissociais e atitudes violentas, que ao fim e ao cabo se revertem na aprovação e crescimento cognitivo e atitudinal ou na evasão e retenção, que desnorteiam e desafiam escolas e educadores (SOUZA, 2017).

De acordo com Silva (2019):

Existem alguns aspectos que precisam ser revistos nessa parceria. Um deles é a questão que muito preocupa os partícipes desse

RC: 84460

Disponível em: https://www.nucleodoconhecimento.com.br/educacao/relacao-escola 
processo, inclusive os professores, gestores e a família do próprio aluno - trata-se da questão da indisciplina. Caso o educando/filho não cumpra as normas da escola, devido à indisciplina, é preciso que os pais, juntamente com a escola, o corrijam. Contudo, em muitas das vezes, o que se vê são pais 'passando a mão na cabeça do filho', acobertando-o e divergindo da escola, e, desse modo, o aluno se beneficia dessas discordâncias, conquistando o que desejava, e, assim, persistindo no mau comportamento (SILVA, 2019, p.3).

Ante esta poderosa influência da família, o desafio que enfrenta a escola é de elaborar um sistema transformador, capaz de enfrentar a complexidade dos problemas e revertê-los em situações positivas (SILVA, 2019).

Segundo Almeida (2018):

\begin{abstract}
O distanciamento familiar da escola tem gerado perdas de ambas as partes, isso porque a cumplicidade e a responsabilidade devem estar divididas na sua proporção para que o sucesso seja real. Vivencia-se uma frequência cada vez menor dos pais nas reuniões da escola, nas visitas que deveriam ser feitas, no diálogo com o corpo docente e direção escolar. Vive-se também por parte dos docentes, a busca por melhorias financeiras e um estresse constante por terem que distribuírem seu tempo em três horários e/ou em duas escolas, atrapalhando uma preparação mais eficiente para exercer as tarefas escolares cada dia mais ampliada (ALMEIDA, 2018, p.7).
\end{abstract}

Naturalmente, nem tudo depende da sistematização da escola e muitos dos problemas estão além de seu raio de ação, dependendo de políticas públicas e redes de apoio que favoreçam a permanência dos alunos na escola e lhes deem condições socioafetivas para um salutar desenvolvimento cognitivo. Todavia, em detrimento das questões político-sociais que transcendem o alcance da escola, esta pode e deve desenvolver instrumentos que garantam a permanência da família no ambiente escolar (ALMEIDA, 2018).

\title{
2.2 A RELAÇÃo FAMÍlIA/ESCOLA COMO PRESSUPOSTO DEMOCRÁTICO
}

Para chegarmos a apontar caminhos significativos de fortalecimento das relações entre família e escola é preciso primeiramente responder a quem cabe a construção

RC: 84460

Disponível em: https://www.nucleodoconhecimento.com.br/educacao/relacao-escola 
dessa relação. É discurso comum nos ambientes escolares a afirmativa de gestores, coordenadores e professores de que por mais que a escola recomende a família pouco interage com a escola. Este discurso está sempre carregado de afetos negativos em vista dos fracassos e dos conflitos de indisciplina, violência, evasão e repetência. Esta percepção reforça um sentimento de apatia, ansiedade, em que se busca o culpado para a ineficiência e o insucesso (ALMEIDA, 2018).

Ainda conforme Almeida (2018), tem-se que:

É a família que constitui a personalidade dos indivíduos em fase inicial, transmitindo conteúdos cognitivos. A subtração da participação familiar na vida escolar do aluno gera na maioria dos casos, um déficit na aprendizagem e, por conseguinte, o insucesso escolar. O fato é que tanto a escola quanto a família precisam um do outro, pois essa interação deve ocorrer para que se garanta o sucesso e o bom desempenho. No entanto, há uma crise instalada nesse contexto, pois a família nuclear perdeu a predominância, abrindo caminho cada vez mais crescente para o conflito de gerações, inseridos nas atuais sociedades e instituições familiares. Contudo, isso não impede da família estar mais presente na vida escolar do aluno, mesmo que não seja como um reforço na aprendizagem das tarefas ou trabalhos escolares, mas como uma incentivadora, uma família capaz de importar-se com o rendimento do aluno, com o crescimento de sua aprendizagem. Para isso, basta estar inserido na escola, participar do andamento da mesma, de seus projetos, dos diálogos promovidos e incentivados pela escola. Trata-se da dialética família/escola, que incentiva uma participação mais sucinta da família e consequentemente o desenvolvimento do trabalho escolar tanto do aluno, quanto do professor (ALMEIDA, 2018, p.11).

No entanto, é importante frisar que sendo a escola e os professores os elementos catalizadores do processo de aprendizagem, a iniciativa de propiciar a interação família-escola cabe aos educadores por serem os elementos-chave da educação (REALI; TANCREDI, 2005). "Transferir essa função à família somente reforça sentimentos de ansiedade, vergonha e incapacidade aos pais, uma vez que não são eles os especialistas em educação" (CAETANO, 2004, p.58). 
Através das palavras de Reynolds e Teddlie (2008 apud OLIVEIRA, 2015):

[...] diversos estudos mostram a relação entre escola e família como sendo uma relação positivamente produtiva ao processo de ensino aprendizagem, de maneira que devem ser analisados em sua especificidade. Apesar dos fortes indícios dessa relação benéfica entre estas duas instituições (família e escola), os autores também apresentam estudos que são mais cautelosos na análise, destacando que se faz necessário considerar, ainda, uma abundância de fatores sociais e contextuais. Embora os mesmos autores realizem, ainda, um levantamento de pesquisas que não conseguiram encontrar 0 envolvimento dos pais como uma relação que resulta em ganhos positivos nas escolas consideradas eficazes, são categóricos ao afirmar que há um volume muito maior de produções acadêmicas que evidenciam o efeito positivo e experiências bem sucedidas de relação escola-família em prol do aprendizado do aluno (REYNOLDS; TEDDLIE, 2008 apud OLIVEIRA, 2015, p.21).

Destarte, é indiscutível que idealmente espera-se das famílias uma participação efetiva no sentido de acompanhar e auxiliar os filhos em suas atividades escolares, acorrendo a escola sempre que convidado para reuniões ou em função de auxiliar em situações de conflito e indisciplina, além, naturalmente, nos momentos de culminância e exposição de projetos produzidos pedagogicamente. Mesmo nestas situações, a presença dos pais e das mães muitas vezes é insuficiente e reforça o discurso negativista quanto ao pouco apoio recebido pelas famílias (OLIVEIRA, 2015).

Esta percepção não chega a ser equivocada totalmente no sentido de que de fato a família pode e deve ter atitudes de corresponsabilidade e interesse dos pais ante as atividades escolares. Todavia, mesmo nestas situações a integração da escola com as famílias assume aspectos de ambiguidade, em que o diálogo se oblitera. Isto porque quem cabe ao professor as competências metodológicas do processo de ensino-aprendizagem. Os responsáveis em geral não necessariamente dispõem da competência científica para responderem a todas essas expectativas. Muitas vezes, as "intromissões" das famílias nas propostas pedagógicas e atividades acaba sendo motivo de atrito entre responsáveis e professores, criando situações de constrangimento e embaraços, fazendo com que os mesmos professores que exigem 
a participação das famílias veem com maus olhos estas interferências (OLIVEIRA, 2015).

Segundo Miranda (2020):

Pode-se considerar que o diálogo é pedagógico, pois possibilita as relações entre os sujeitos da educação. Nesse sentido o diálogo permite a formação de estruturas mais democráticas dentro das realidades sociais contribuindo para que todos se estabeleçam em lugares paritários e possam caminhar rumo à sociedade mais liberadoras e menos injustas. Em contrapartida, quando há ausência de diálogo, revela-se o autoritarismo nas relações pedagógicas, que pressupõe relações verticais, onde alguns detêm o poder e os demais são relegados a condição de servir (MIRANDA, 2020, p.7).

Isto se dá porque ainda é prática convencional da escola propiciar um diálogo unilateral e dirigido com a escola. Em verdade, estas estratégias para favorecer a presença da família na escola se dão com funções marcadas e distribuição de papéis dirigidos, sem que de fato tenha havido um verdadeiro enlace que oportunizasse, também, à comunidade escolar além de uma função de expectadora e receptora do que lhe é delegado (MIRANDA, 2020).

Para se transcender a esse círculo vicioso de um diálogo unilateral é de fundamental importância reinventar os espaços. Fazer da escola um ambiente de convivência democrática em que todos interajam com igual poder de participação sem que com isso haja interferência e invasões às responsabilidades e competências de cada um dos sujeitos do processo (MIRANDA, 2020).

[...] a sociedade é, além do mais, um grande agrupamento social, que comporta inúmeros subgrupos (família, escola, etc). Aprender a conviver em grupos é uma forma de preparar-se para a vida social. a importância do grupo está também em propiciar a aprendizagem de papéis sociais diferentes e complementares na organização social como um todo. Assim, viver democraticamente na escola, expressar opiniões, aprender a ouvir respeitar a opinião alheia, identificar as verdadeiras lideranças, organizar-se em torno delas, são as virtudes democráticas que, aprendidas na escola, serão transportadas para a vida social (PIMENTA, 1991, p.128).

RC: 84460

Disponível em: https://www.nucleodoconhecimento.com.br/educacao/relacao-escola 
Responsáveis, alunos, professores são todos atores da produção de saberes. Todos têm suas responsabilidades, seus objetivos e suas percepções de mundo. Permitir que cada uma dessas vozes se faça presente no espaço e no tempo pedagógico depende de a escola predispor-se em seu projeto político-pedagógico a ofertar uma escola aberta às multiplicidades de vozes, de saberes, de percepções e compreensões. Criar uma via de mão dupla, em que tanto a família vá a escola, quanto esta supere seus muros e vá ao encontro da comunidade. Não é tarefa das mais simples e das mais fáceis, é verdade (PIMENTA, 1991).

No que tange a estes aspectos, Pimenta (2014) exalta que:

Família e escola representam duas instituições fundamentais no processo de educação do indivíduo. Em diferentes momentos históricos foram marcadas por expectativas acerca do seu desenvolvimento e na atualidade encontram-se intrinsecamente interligadas por papéis e funções muitas vezes confundidos entre si. A importância destas duas instituições para a formação plena do ser humano é indiscutível e cada vez mais se evidenciam os problemas e conflitos causados pelas divergências acerca de suas funções (PIMENTA, 2014, p.181).

Até pela falta de investimento e de incentivo, muitos professores frequentam as instituições escolares como ilhas passageiras, muitas vezes mal tendo a oportunidade de conhecer plenamente a comunidade a quem ele atende. Sua percepção das famílias passa muitas vezes apenas pelo contato única e simplesmente com seus alunos, sem reconhecer-Ihes ou conhecer a fundo seus modos e condições de vida, em que creem, quais seus hábitos e valores culturais. Cerceados pelos muros, assoberbados de conflitos, enfrentando as mais diversas situações de fracasso de muitas crianças e jovens, os professores e, com eles, a escola acabam cedendo a apatia e ao sentimento de incapacidade, causadores de adoecimento emocional de tantos e tantos profissionais de educação (PIMENTA, 2014).

Silva (2014) evidencia que:

Enquanto construção individual e coletiva, a vivência também requer o compartilhamento de significados comuns ao contexto histórico e

$\mathrm{RC}: 84460$

Disponível em: https://www.nucleodoconhecimento.com.br/educacao/relacao-escola 
cultural de modo a permitir a vida social. Porém, família e escola discursam desejarem estar integradas, mas, encontram-se em desacordo nos significados construídos em torno das práticas da relação. O processo de significação acontece em posições distintas e distantes entre família e escola como sendo dois contextos separados e pouco conectados entre si (SILVA, 2014, p.133).

Só se atingirá uma participação efetiva das famílias nos processos escolares e destes na organicidade daquelas se politicamente a escola se abra para a construção de conhecimentos partilhados: saberes formais e escolares, saberes comunitários e culturais, saberes éticos e saberes políticos. É verdade que pela própria transformação da sociedade, pelos avanços nas pesquisas pedagógicas e na pressão que as transformações exercem sobre as escolas, estas estão a meio caminho deste desenvolvimento. Já se consolida, embora com altos e baixos, a percepção metodológica de dar aos alunos protagonismo na construção de seu conhecimento, de dialogar com seu repertório de vida e com o conhecimento prévio, favorecendo sua autonomia e independência (SILVA, 2014).

Para Souza (2020):

Quanto ao apoio e trabalho em conjunto nas escolas, muitas são as dificuldades enfrentadas pelas famílias. Destacam-se questões sociais, econômicas, financeiras e até mesmo pessoais, que acabam interferindo no meio familiar causando desequilíbrio a ponto de não conseguirem apoiar seus filhos no processo de aprendizagem. O que reflete um grande problema, visto que o envolvimento da família na vida escolar dos filhos é apontado como principal fator de sucesso. Assim como a escola tem suas responsabilidades perante o aluno, os pais precisam acompanhar o desenvolvimento desta aprendizagem e estar atentos às necessidades dos mesmos, não só cobrando resultados, mas também se fazendo presentes contribuindo nas tarefas, participando de reuniões, eventos, conversando com professores e orientadores, ou seja, se permitindo uma aproximação maior com os filhos e com a escola a respeito do ensino e tudo que 0 envolve no contexto familiar e social (SOUZA, 2020, p.5).

Apesar das dúvidas e ambiguidades, a opção das escolas por pedagogias de projeto muito tem contribuído para estes avanços. Faz-se necessário que em seus projetos políticos-pedagógicos as instituições de ensino democratizem o seu fazer, promovendo projetos com vias de mão dupla, compartilhando saberes que sejam

RC: 84460

Disponível em: https://www.nucleodoconhecimento.com.br/educacao/relacao-escola 
levados às casas e às comunidades, visando interferir positiva e dinamicamente na vida comum das famílias, ao mesmo tempo em que se abra a presença das famílias igualmente compartilhando saberes e fazeres por meio de oficinas, parcerias em projetos escolares, associações de pais e mestres, escolas de pais, em sistema de cooperação constante para que a escola veja sentidos e significados naquilo que oferecem ao mesmo tempo em que as famílias sintam-se parte da construção coletiva de saberes e liberdades (SOUZA, 2020).

Com esta percepção, Paro (2000) ressalta a importância da participação de se dar voz e escuta às expectativas dos pais no ambiente escolar:

Uma dimensão importante da participação dos pais na escola, seja integrando o conselho de escola ou a APM, seja tomando parte de outras atividades, como o grupo de formação de pais, é da atenção que se deveria ter para com os motivos dessa participação, procurando saber qual o ponto de vista dos usuários a respeito (PARO, 2000, p.120).

Obviamente muito deste ideal depende de uma mudança significativa do interesse da sociedade e dos poderes instituídos em criar condições para essa revolução nos processos escolares, mas cabe a escola e aos educadores investir-se de sua própria autoridade para iniciar este gesto político (PARO, 2000).

\section{METODOLOGIA}

Este estudo apresenta uma abordagem qualitativa, que de acordo com Gerhardt e Silveira (2009, p.31), "não se preocupa com representatividade numérica, mas, sim, com o aprofundamento da compreensão de um grupo social, de uma organização, etc.". De natureza básica que intenciona gerar novas fontes de pesquisa para novos autores com novos conhecimentos gerados a partir da pesquisa bibliográfica.

A pesquisa bibliográfica é feita a partir do levantamento de referências teóricas já analisadas, e publicadas por meios escritos e eletrônicos, como livros, artigos científicos, páginas de web sites. Qualquer trabalho científico inicia-se com uma pesquisa bibliográfica, que permite ao pesquisador conhecer o que já se estudou sobre o assunto.

RC: 84460

Disponível em: https://www.nucleodoconhecimento.com.br/educacao/relacao-escola 
Existem, porém, pesquisas científicas que se baseiam unicamente na pesquisa bibliográfica, procurando referências teóricas publicadas com o objetivo de recolher informações ou conhecimentos prévios sobre o problema a respeito do qual se procura a resposta (FONSECA, 2002, p. 31).

Tem-se aqui, uma pesquisa baseada unicamente na pesquisa bibliográfica como mencionado em Fonseca (2002), e de objetivo exploratório, que segundo Gerhardt e Silveira (2009, p.35), "tem como objetivo proporcionar maior familiaridade com o problema, com vistas a torná-lo mais explícito ou a construir hipóteses".

\section{RESULTADOS E DISCUSSÃO}

Buscar o envolvimento dos pais no processo educacional dos filhos não deveria ser tarefa da escola, mas ações permanentes e construtivas dos mesmos.

A conscientização dessa relação, atualmente se faz necessária e em muitos casos obrigatoriedade da instituição escolar. Neste contexto cabe uma reflexão sobre a responsabilidade do ensino e aprendizagem do educando.

Carvalho (2018) explana que:

Quando nos remetemos sobre o papel que a escola exerce, devemos lembrar a quem essa instituição serve, o que ela desempenha, quando e de que maneira o faz. Dessa forma, faz-se necessário lembrarmos, como vimos anteriormente, que o fazer da escola era totalmente pautado somente em o indivíduo aprender o básico da leitura e escrita, para assim, atender às exigências e necessidades de adaptação ao mercado de trabalho. Vemos aí, então, que não havia primeiramente uma preocupação com a formação, desenvolvimento e aprendizagem do sujeito. Mas, o tempo vem e as mudanças ocorrem, diante disso, a escola também se modifica. Sendo assim, esta instituição traz o aluno à tona, de forma ativa, impulsionando este a pensar, além dos moldes curriculares, contribuindo na formação de um sujeito crítico e que intervenha na sua realidade (CARVALHO, 2018, p.10).

Este estudo proporcionou momentos de reflexão acerca da relação escola e família em uma proposta democrática. Compreender a importância das duas instituições na formação cognitiva e afetiva dos educandos. O objetivo não foi encontrar culpados

RC: 84460

Disponível em: https://www.nucleodoconhecimento.com.br/educacao/relacao-escola 
para possíveis fracassos, mas refletir sobre as convergências e divergências em uma dimensão ampla e geradora de propostas eficazes que garanta condições e possibilidades para que o estudante adquira conhecimentos necessários para seu desenvolvimento dentro de uma sociedade.

\section{CONSIDERAÇÕES FINAIS}

É indiscutível que a nossa sociedade se pauta, ou deveria pautar, em todos os seus aspectos pelos princípios e valores da democracia. Incluam-se aí, a necessidade de politização e participação de todos os indivíduos nas decisões voltadas para o bem comum. Se este é o bem maior da sociedade, este deve sê-lo também para a educação e para a escola. Sob essa lógica é que se torna imprescindível à escola contemporânea a existência de um projeto que dê espaço, vez e voz aos pais e às mães dentro do ambiente escolar.

Neste contexto, a democratização consiste numa certa descentralização do poder, promovendo a participação dos vários segmentos da comunidade escolar, inclusive com direito à tomada de decisões e/ou a fazer proposições significativas para a vida e a respiração da escola. Sabe-se, igualmente que a consciência da democracia nasce do seu exercício e de sua prática. Se a comunidade não participa política e ativamente da vida da escola de certa forma deslegitima o contrato social de uma gestão democrática.

Todavia, o que vemos, muitas das vezes, são parcelas mínimas da comunidade, especialmente de pais e mães, envolvidos no processo de educação das crianças e jovens, enquanto a maioria sequer toma conhecimento do que se dá no ambiente da escola, de seus sucessos e de suas dificuldades.

É preciso, por isso, que nos conscientizemos da necessidade de criar uma cultura democrática dentro da escola, especialmente na sociedade brasileira que foi vítima por quase trinta anos de regimes autoritários. Há pouco mais de vinte anos é que resgatamos o direito ao voto e à participação democrática. Somos ainda uma

RC: 84460

Disponível em: https://www.nucleodoconhecimento.com.br/educacao/relacao-escola 
sociedade marcada pelo silêncio, de modo que, para que retomemos o curso da democracia, precisamos reinseri-la na cultura, e isso só se dá quando investirmos em todas as possibilidades, fecundando toda a escola com as mais diversas formas de participação política.

Enfim, é fato indiscutível que a democracia se aprende na escola. Mas para isso fazse necessário que a vida da escola seja preenchida de situações democráticas. Eleições para diretores, eleições de formação de grêmios, assembleias de alunos, assembleias de pais, assembleias dos conselhos, com debates pertinentes e significativos para a comunidade escolar. Só se respirarmos democracia, fazendo da escola a ágora das grandes discussões, vivificaremos os conselhos e vivenciaremos a democracia no seu mais amplo significado.

\section{REFERÊNCIAS}

ALMEIDA, Hélio Mangueira de. Problemas Contemporâneos da Educação: Escola e Família. Revista Científica Multidisciplinar Núcleo do Conhecimento. Ano 03, Ed. 06, Vol. 05, pp. 17-24, Junho de 2018. ISSN:2448-0959 Disponível em: https://www.nucleodoconhecimento.com.br/educacao/problemas-contemporaneos Acesso em: 20 dez. 2020.

CAETANO, L. M. Relação escola e família: uma proposta de parceria. Dialógica, v. 1, 51-60, 2004.

CARVALHO, Francisca Aparecida Nayara. Impacto da relação entre família e escola no desempenho acadêmico do aluno. Revista Científica Multidisciplinar Núcleo do Conhecimento. Ano 03, Ed. 08, Vol. 13, pp. 111-139, Agosto de 2018. ISSN:2448-0959 Disponível em: https://www.nucleodoconhecimento.com.br/psicologia/familia-e-escola Acesso em: 20 dez. 2020.

FONSECA, J. J. S. Metodologia da pesquisa científica. Fortaleza: UECE, 2002.

RC: 84460

Disponível em: https://www.nucleodoconhecimento.com.br/educacao/relacao-escola 
GERHARDT, Tatiana Engel; SILVEIRA, Denise Tolfo. Métodos de Pesquisa. Porto Alegre: Editora da UFRGS, 2009.

KREPPNER, K. As crianças e a família: Interdependência nos meios de desenvolvimento. Psicologia: Teoria e Pesquisa, 2000.

MIRANDA, Tânia Márcia Oliveira de. A importância da afetividade no vínculo escolar e família na aprendizagem do aluno. Revista Científica Multidisciplinar Núcleo do Conhecimento. Ano 05, Ed. 12, Vol. 12, pp. 05-17. Dezembro de 2020. ISSN: 2448-0959 Disponível

em: https://www.nucleodoconhecimento.com.br/educacao/afetividade-no-vinculo Acesso em: 10 jan. 2021.

OLIVEIRA, André Luiz Regis de. Entre a escola e a família: nuances de um (des) encontro. 2015. 158f. Dissertação (Mestrado em Educação) - Departamento de Educação, Pontifícia Universidade Católica do Rio de Janeiro, Rio de Janeiro, 2015.

PARO, Vitor Henrique. Qualidade do Ensino: A contribuição dos pais. São Paulo: Xamã, 2000.

PIMENTA, Juliana de Carvalho. A relação família - escola: concepções e práticas. 2014. 245f. Tese (Doutorado em Serviço Social) - Faculdade de Ciências Humanas e Sociais, Universidade Estadual Paulista “Júlio de Mesquita Filho", Franca, 2014.

PIMENTA, Selma Garrido. O Pedagogo na Escola Pública. São Paulo: Loyola, 1991. POLÔNIA, Ana da Costa; DESSEN, Maria Auxiliadora. Em busca de uma compreensão das relações entre família e escola: relações família-escola. Psicologia Escolar e Educacional, p. 303-312, 2005.

REALI, A. M. M. R., \& TANCREDI, R. M. S. P. A importância do que se aprende na escola: a parceria escola-famílias em perspectiva. Paidéia, 15 (31), 239-247, 2005.

$\mathrm{RC}: 84460$

Disponível em: https://www.nucleodoconhecimento.com.br/educacao/relacao-escola 
REYNOLDS, David; TEDDLIE, Charles. Os processos da eficácia escolar. In: BROOKE, N; SOARES, J. F. (Org.). Pesquisa em eficácia escolar: origem e trajetórias. 1ed. Belo Horizonte: Editora UFMG, 2008. 552p. 297-334.

SILVA, Demóstenes Neves da. Significações de pais e professores sobre a relação família-escola: as armadilhas de um (des)encontro. 2014. 199f. Tese (Doutorado em Psicologia) - Instituto de Psicologia, Universidade Federal da Bahia, Salvador, 2014.

SILVA, Wilson Ribeiro da. Parceria entre escola e família: rumo a uma gestão democrática e participativa de qualidade. Revista Científica Multidisciplinar Núcleo do Conhecimento. Ano 04, Ed. 09, Vol. 06, pp. 63-70. Setembro de 2019. ISSN: 24480959 Disponível em: https://www.nucleodoconhecimento.com.br/educacao/escola-efamilia Acesso em: 20 jan. 2021.

SOUZA, Adriana Izaías De Azevedo. A relação entre a família e a escola no processo de ensino e aprendizagem. Revista Científica Multidisciplinar Núcleo do Conhecimento. Ano 05, Ed. 01, Vol. 01, pp. 134-144. Janeiro de 2020. ISSN: 24480959, Disponível

em: https://www.nucleodoconhecimento.com.br/educacao/processo-de-ensino Acesso em: 10 jan. 2021.

SOUZA, Oralda Adur de. Família-escola e desenvolvimento humano: um estudo sobre atitudes educativas familiares. 2017. 155f. Tese (Doutorado em Educação) Faculdade de Educação, Universidade Federal do Paraná, Curitiba, 2017.

Enviado: Janeiro, 2021.

Aprovado: Maio, 2021.

RC: 84460

Disponível em: https://www.nucleodoconhecimento.com.br/educacao/relacao-escola 